\title{
Rüsen e Ankersmit
}

\author{
Luiz Sérgio Duarte da Silva \\ Prof. Adjunto da Faculdade de História da Universidade federal de Goiás \\ duarte@historia.ufg.br
}

Como citar este artigo: Silva, Luiz S. D. "Rüsen e Ankersmit". Intelligere, Revista de História Intelectual, vol. 3, n², p. 5459. 2017. Disponível em < http://revistas.usp.br/revistaintelligere>. Acesso em dd/mm/aaaa.

Resumo: Este artigo procura o que interessa a Rüsen (nascido em 1938) na obra de Ankersmit e o que interessa a Ankersmit (nascido em 1945) na obra de Rüsen. Justifica-se tal intento de aproximação partindo da importância, consistência e influência das obras desses dois teóricos vivos e atuantes da história e no interesse, central na obra destes dois filósofos da história, na atualização do Historismo.

Palavras-chave: Jörn Rüsen; Ankersmit; Historismo; interpretação.

\section{Rüsen and Ankersmit}

\begin{abstract}
This article looks at what interests Rüsen (born in 1938) in Ankersmit's work and what interests Ankersmit (born 1945) in Rüsen's work. Such an attempt to approximation is justified by the importance, consistency and influence of the works of these two living and active theoreticians of history and in the interest, central to the work of these two philosophers of history, in the actualization of Historism.
\end{abstract}

Keywords: Jörn Rüsen; Ankersmit; Historism; interpretation. 
I.

A diferença entre interpretação e representação é fundamental para a solução de problemas procedurais da ciência da História. Ciência é atividade racional de conhecimento caracterizada por controle lógico e empírico de seus enunciados. A interpretação é resultado de um processo cognitivo regulado metodicamente. Quem interpreta tem que se limitar pela coisa que quer interpretar, pelo esquema teórico que utiliza para encaminhar a interpretação e pela crítica da explicação que ela (a interpretação) produz. A forma da explicação da história é a compreensão da relação que media texto (parte) e contexto (todo) em rua de mão dupla. Para Rüsen, essa "nítida distinção" foi " evidenciada"1 por Ankersmit em Meaning, Truth and Reference. $^{2}$ Para Rüsen, há duas dimensões da experiência da interpretação. Uma primeira advém do trabalho com as fontes. $\mathrm{O}$ historiador precisa posicionar-se em uma área, localizar uma documentação e distinguir nela o que é relevante para a resposta à pergunta que formulou. A heurística é a primeira parte das operações processuais da metodologia da história. As outras são a crítica (como obtenção de informações comprováveis, a saber, a crítica externa ou estabelecimento da autenticidade e a crítica interna ou produção de fidedignidade) e a interpretação. Os resultados da interpretação são controlados intersubjetivamente. É por isso que a argumentação e as referências são centrais em todo o processo de produção de garantia da validade empírica das histórias. ${ }^{3}$ Rüsen complementa sua metodologia da história com a exposição das suas (da metodologia) operações substanciais. São as concepções de método: a hermenêutica ou tratamento dos contextos de sentido, a analítica ou exame das circunstâncias externas do agir, e a dialética ou o desenvolvimento das relações complexas entre hermenêutica e analítica. A investigação da experiência histórica em Ankersmit é utilizada por Rüsen para enfatizar a especificidade da operação de organização do material encontrado na pesquisa. Rüsen é conhecido e valorizado em Teoria da História por defender um tipo de reflexão sobre o caráter narrativo do conhecimento histórico sem abrir mão da preocupação com a sua objetividade. O caráter narrativo do conhecimento histórico é marcado pela produção do enredo ou plot. Este é objeto de outro elemento da matriz disciplinar de Rüsen, a tópica, ou teoria das formas da historiografia. São tipos de narrativa (tradicional, exemplar, crítica e genética). Essa tipologia contempla os processos através dos quais as leituras do passado produzem identidade e orientação na forma de textos. A narrativa é a exposição textual unificada (um todo composto por início, meio e fim) de um significado atribuído a um pedaço de passado. No enredo a forma de representação da mudança temporal está associada ao significado que a história narrada deve possuir para pertencer ao mundo do sentido, ou seja, ao mundo das coisas que substituem, vale dizer, ao mundo humano. A narrativa reapresenta aquilo que foi conhecido pelo trabalho de interpretação. A teoria da representação como teoria da narrativa histórica é a grande contribuição de Ankersmit para a Teoria da História em Narrative Logic, livro de 1983. ${ }^{4}$ Trata-se da exposição do tipo de explicação narrativa (a estória) e de suas características (a frase narrativa, frase com dupla historicidade e substância narrativa, todos ou significados do passado). Importa fixar que Rüsen, assim como Ankersmit, é narrativista. Sua teoria da narrativa está filiada a Arthur Danto (a investigação da relação entre explicação histórica e narrativa) e a Hans Michael Baumgartner (a reflexão sobre a relação entre continuidade e história).

O projeto de renovação do historicismo de Rüsen ${ }^{5}$ baseia-se na constatação de que o pluralismo de valores (resultante da quebra da unidade entre individualidade e história, o sonho iluminista herdado pelo historicismo) é uma vantagem. Ele nos previne contra a solução

\footnotetext{
${ }^{1}$ Jörn Rüsen, Historik (Köln: Böhlau, 2013), 188

2 Frank Ankersmit, Meaning, Truth, and Reference in Historical Representation (New York: CUP, 2012).

${ }^{3}$ Jörn Rüsen. Reconstrução do Passado - Teoria da História II: os princípios da pesquisa histórica. Trad. Asta-Rose Alcaide e Estevão de Rezende Martins. Brasília: Ed. da UNB, 2007, 102 - tradução de Jörn Rüsen, Rekonstruktion der Vergangenheit (Göttingen: V und R, 1986).

${ }^{4}$ Frank Ankersmit. Narrative Logic: a Semantic Analysis of the Historians Language (London: MNP, 1983).

${ }^{5}$ Jörn Rüsen, Zeit und Sinn (Frankfurt am Main: Fischer, 1990).
} 
dogmática e objetivista, por um lato, e nos permite incorporar a dimensão literária do trabalho do historiador, por outro. Reconhecer que o fundamento da autonomia e especificidade da ciência da história reside no seu caráter narrativo resolve um problema de relação entre teoria e prática. Essa relação havia sido concebida pelo Historismo através da unificação das dimensões individual e universal, do espírito humano. Sabemos que o preço dessa solução foram tanto o objetivismo (a positivação dos fatos) como o dogmatismo (o determinismo das leis da história). Rüsen quer salvar a criança e jogar fora a agua suja. Trata-se de resgatar o caráter humanista do projeto unificador: a renovação do historicismo é uma possível consequência da descoberta da relação entre valor e contexto. O relativismo enquanto teoria da verdade é um impulso para o fortalecimento da verdade científica. As coisas humanas só podem ser conhecidas contextualmente. Compreensão, no entanto, não deve nos afastar de procedimentos formalizadores e comparativos. Ela apenas nos capacita a perceber que as formas de representação das coisas humanas estão intimamente conectadas com os interesses de orientação de seus produtores. Mais que isso, esses interesses são plurais e nada nos conteúdos fáticos do que fizeram os seres humanos poderá resolver definitivamente os dilemas que a cada momento nos são apresentados. Só podemos contar com nossa capacidade de selecionar o problema a ser abordado em cada situação, reunindo as referências materiais adequadas, escolhendo corretamente as estratégias de tratamento e exposição e assumindo as funções e motivos que orientam, em cada situação e para cada objeto, esse esforço.

Um dos significados do termo Historismo é o que identifica nele uma crise de orientação do pensamento histórico ocorrido no final de século XIX. Desde a passagem do Iluminismo para o Romantismo, a forma da consciência do tempo passou a ser aquela que a entende a partir de condições históricas. Ser moderno é pensar historicamente. Depois da afirmação da centralidade da humanidade e depois do sonho da harmonia entre história e individualidade temos a quebra dessa sequência de diferentes ênfases de um pensamento humanista. Esse movimento é o de afirmação e crise da filosofia da história. A criatividade humana, corporificada seja em obras ou instituições não mais estava em acordo com o sentido do tempo. O tempo humano, a história, perde seu sentido. Esse é o problema do historicismo localizado por Troeltsch. Renovar o historicismo é valorizar o pluralismo de sentidos e encontrar as condições (crítica da cultura, valorização da ciência e da arte) de sobrevivência da forma histórica de ver as coisas humanas.

“A Sublime Dissociação do Passado", título de um artigo de Ankersmit, é usado por Rüsen ${ }^{6}$ como máxima que resume uma qualidade universal do ser humano: a interpretação da mudança temporal. A perda do passado se torna suportável graças à sua atualização. Nesse sentido, o ser humano se torna o que ele não mais é. A interpretação é uma forma de identificação. O passado se torna história e o que passou pode ser melhorado. No trecho em que cita Ankersmit, Rüsen cita também Shakespeare e a frase de Hamlet "The World ist out of joint, oh cursed spite, that ever I was born to set it right". Só pela interpretação podemos encontrar nosso lugar no mundo. A história é a disciplina que nos ensina a interpretar o tempo, por isso ela é central. A relação entre passado, presente e futuro que a fenomenologia de Husserl, Heidegger e Gadamer encaminharam é a referência para uma teoria da história, que nos moldes de Droysen, quer ser sistemática e construtiva. Nesse sentido, o da afirmação da construtividade do saber histórico, Droysen antecipou a teoria da história pós-moderna. Rüsen propõe uma radicalização dessa antropologia: uma lógica da reconstrução deve substituir pósmetafisicamente a lógica teleológica. Da mesma forma que a aspiração por liberdade de Aristóteles produziria as condições da comunicação intercultural a própria aspiração pelo futuro da humanidade alimentaria a reconstrução do passado. Em Rüsen, os fins do homem são substituídos pela pesquisa da gênese da humanidade. As mudanças na concepção da relação entre passado, presente futuro são fundamentais para essa perspectiva. As descobertas

${ }^{6}$ Jörn Rüsen, Kultur Macht Sinn (Köln: Böhlau: 2006), 138. 
sobre a experiência do tempo de Ankersmit são de grande valia para a teoria da história de Rüsen.

A compreensão do historicismo como saber histórico de caráter construtivo tem que ser entendida como avanço no fortalecimento disciplinar da História. A diferença de estratégias de defesa do Historismo entre os teóricos aqui abordados aqui aparece claramente. Entre Iggers (o fim do Historismo) e Ankersmit (a atualidade do Historismo), Rüsen permanece ao lado de Cassirer que não reconhece ruptura entre as duas épocas (e seus modelos de tratamento das coisas humanas) e afirma no Historismo a continuidade do projeto moderno. Seja através da discussão sobre seu status moderno ou pós-moderno, ou pelo caráter de sua função cultural ou como fundamentação da cientificidade do conhecimento histórico, o Historismo viverá de suas crises ainda muito entre nós. ${ }^{7}$ A solução de Rüsen é simples: a) a cientificidade do conhecimento histórico depende de sua relação com as necessidades de orientação inerentes ao agir humano; b) a compreensão como juízo histórico atual é o procedimento das ciências humanas: relatividade de códigos não se pode confundir com relativismo de saberes; c) a historicidade da condição moderna impõem a mudança temporal dos princípios de orientação cultural: a humanidade só pode contar com sua história para encontrar saídas para os dilemas que ela cria e enfrenta.

Já em um artigo de $1986^{8}$ Ankersmit cita Rüsen como uma das exceções à tendência de condenação do Historismo através da condenação que advém de sua identificação e redução ao relativismo ético. A censura dirige-se à Ranke e sua afirmação de que a tarefa dos historiadores é mostrar o que realmente aconteceu e não ensinar lições. Teríamos aí um passado autônomo e a confusão de normas (ligadas ao tempo) com sua aplicabilidade (independentemente do tempo). Mandelbaum, Heussi e Iggers são os responsáveis por essa leitura. A discussão sobre a escrita da história foi esquecida. A censura da especulação dispensou junto com o determinismo, a crítica da cultura e junto com a teleologia, a descoberta perde-se a descoberta do vínculo entre humanidade e história. Desconsiderou-se a fonte da historiografia dos últimos dois séculos e a referência para reflexão sobre as práticas modernas da leitura do passado. Para Ankersmit, Rüsen é também o responsável por localizar a mudança paradigmática de estruturas macro-históricas por situações micro-históricas e cotidiado. ${ }^{9}$ Rüsen é também aquele que discute a história social como último elo na corrente de aspirações essencialistas da História. A mistura de fatos e ideias, a procura pela essência do passado, o otimismo da autosuperestimação, a crença na existência de uma chave que abra todas as portas da história. Para Ankersmit, Rüsen é um aliado na denúncia do essencialismo, no projeto de atualização do Historismo e no resgate da discussão sobre a escrita da história. Ankersmit quer se afastar do contextualismo e valoriza a metáfora como produtora de unidade e coerência: a principal metáfora historicista é a da "profundidade". Um historicista da velha escola considerava "profunda" a identidade ou essência da nação, instituição ou classe. Tal essência era encontrada na história. Sobretudo, é a aproximação da Teoria da História com a Antropologia que é valorizada: há tempos e espaços da vida humana que não podem ser subsumidos na concepção genética do vir-a-ser moderno.

\section{II}

Aqui surge o cerne do problema da relação entre os dois teóricos. O que significa atualizar o historicismo? Para Ankersmit os historiadores trabalham com duas coisas: substâncias narrativas (metáforas) e experiências (sangue, suor e lágrimas). O primeiro tipo sofre pressão da linguagem, o outro, da realidade. O programa é atualizar o Historismo

\footnotetext{
${ }^{7}$ Jörn Rüsen, Geschichte im Kulturprozess (Köln: Böhlau, 2002), 38

${ }^{8}$ Frank Ankersmit, History and Tropology: the Rise and Fall of Metaphor (Berkeley: UCP, 1994), 46.

${ }^{9}$ Frank Ankersmit. History and Tropology, 174.
} 
afastando-o das essências com as quais ele criou uma leitura da humanidade (história, progresso, razão) e, ao mesmo tempo, aceitar a tensão entre coisas de linguagem e coisas de realidade que o próprio historismo instalou no pensamento histórico moderno durante o debate com o Iluminismo e sua ênfase epistemológica. O cerne desse movimento é a criação de um conceito de experiência histórica (intimidade sublime do encontro com o passado possibilitado pela pesquisa). Minha tese é a de que essa atenção para a experiência histórica tem o sentido de crítica à redução do conhecimento histórico a seus aspectos narrativos. Só a renovação das interpretações - entendidas não como leituras dirigidas por esquemas ou construtos engessados por contextos, mas como resultado experimental de investigação pode nos orientar na manutenção do projeto de conhecimento das diferentes formas da experiência do mundo. O paradoxo do Historismo é que a defesa da tese de que a substância só pode ser conhecida no tempo implica a ideia de mudanças substanciais: a sincronia ataca o âmago da diacronia. Todo pesquisador do Historismo sabe que uma valorização das diferenças é o que resulta da aceitação do princípio de que a essência de uma entidade histórica está em sua história. Ankersmit aproxima Burkhardt e a história das mentalidades na defesa da independência de cada fase da evolução histórica. Com a ajuda de Rüsen, surge assim um Historismo que não tem problema com a fragmentação. ${ }^{10}$

Para Ankersmit, o Historismo é uma invenção alemã, praticada hoje no mundo anglosaxão (uma versão light) como atualização de Colingwood. A discussão deve ultrapassar a questão do que foi o Historismo e avançar para o nível de reflexão sobre como ele pode contribuir para o debate atual. ${ }^{11}$ Não há objetos fixos reconhecíveis. Os objetos são fixados e essa definição tem história. Esse é o problema do efeito do real: o texto cria mais que reflete. Só um realismo ingênuo ignora que linguagem e realidade se confundem no mundo da cultura, dos símbolos ou valores. Este é o mundo da representação como substituição. O objetivismo, a teoria da verdade como coincidência, e o referencialismo não dão conta dele. $\mathrm{O}$ textualismo também não: ele é outra forma de redução que esquece a diferença entre escrita e pesquisa. A filosofia da história pode e deve contribuir para a filosofia da ciência. As soluções realistas ou instrumentalistas não ajudam no império dos sentidos. Não há solução final, uma receita, uma chave para tudo. Só temos conhecimento provisório e refutável. O que conseguiremos - se conseguirmos - é continuar trabalhando em um mundo tenso, carregado das pressões que nos chegam da linguagem e do real. Trata-se de não ter medo das misturas. Isso não quer dizer que esforços de delimitação são infrutíferos: precisamos também de limites. Mas sempre haverá áreas ainda não submetidas a escrutínio. É essa abertura pluralista que aproxima Rüsen e Ankersmit.

No caso de Rüsen, a atualização do Historismo está na releitura de Droysen, na primeira e a segunda versão da Historik, nos livros sobre os seus vários momentos e vertentes e nos esforços de comparação de variantes do pensamento histórico como versões de humanismo. A crise do Historismo é uma crise da ideia dos valores eternos sob influxo do neo-kantismo. A solução heideggeriana (o historicismo individual) ou a problemática relação entre filosofia da linguagem e holismo (autonomia da linguagem e ataque à referência) são duvidosas. Melhor é manter a tensão e reforçar todas as tentativas de resgate do pensamento individualizador. ${ }^{12}$

O pensamento individualizador baseia-se na ideia de que a ação modificadora é análoga à criação da obra de arte (Rüsen a localiza na leitura de Goethe realizada por Meinecke). Cita também como referência a teoria da forma da história em von Humboldt (expor cada evento como parte de um todo exige tratamento poético). Ela está presente também na tese rankeana de que da história é constitutiva uma duplicidade de elementos cognitivos (interpretação

${ }^{10}$ Frank Ankersmit, Historical Representation (Stanford: SUP, 2001), 34.

${ }^{11}$ Frank Ankersmit, Meaning, Truth, and Reference in Historical Representation (New York: CUP, 2012), 5

12 Jörn Rüsen, Konfigurationen des Historismus (Frankfurt am Main: Suhrkamp, 1993), 350. 
controlada) e não-cognitivos (representação como substituição). A história é ciência e arte ao mesmo tempo. ${ }^{13} \mathrm{~A}$ tensão entre objetividade e narratividade ou entre linguagem e realidade é mais produtiva que qualquer solução unilateral.

${ }^{13}$ Jörn Rüsen, Historik (Köln: Böhlau, 2013), 192. 